\title{
Stimulation of ovarian oxytocin secretion and uterine prostaglandin release by exogenous progesterone early in the cycle of the ovarian auto-transplanted ewe
}

\author{
H. Y. Al-Matubsi ${ }^{1}$, J. Downing ${ }^{2}$, G. Jenkin ${ }^{3}$ and R. J. Fairclough ${ }^{4}$ \\ ${ }^{I}$ Centre for Bioprocessing and Food Technology, Victoria University of Technology, Werribee Campus, \\ PO Box 14428 MCMC, Melbourne, VIC 8001, Australia; ${ }^{2}$ CSIRO, Division of Animal Production, \\ Prospect, LMB 1 Delivery Centre, Blacktown, NSW 2148, Australia; ${ }^{3}$ Department of Physiology, Monash \\ University, Clayton, VIC 3168, Australia; and ${ }^{4}$ Department of Biomedical Sciences, Victoria University of \\ Technology, St Albans Campus, PO Box 14428 MCMC, Melbourne, VIC 8001, Australia
}

\begin{abstract}
The present study was undertaken to determine whether the administration of progesterone, early in the oestrous cycle, had an influence on ovarian oxytocin secretion and on peripheral concentrations of the prostaglandin $\mathrm{F}_{2 \alpha}$ metabolite 13,14-dihydro-15-keto $\mathrm{PGF}_{2 \alpha}$ (PGFM) in the ovarian auto-transplanted ewe. Twelve ewes with ovarian auto-transplants $(n=6$ per group) were randomly assigned to receive an i.m. injection of progesterone $(12.5 \mathrm{mg})$ or vehicle, twice a day, on days 1,2 and 3 of the oestrous cycle. Beginning on day 7 , blood samples were collected at intervals of $1 \mathrm{~h}$ from the ovarian and contralateral jugular veins for up to $70 \mathrm{~h}$. Ovarian oxytocin secretion rate and jugular concentrations of PGFM and progesterone were determined by radioimmunoassay. The number of ewes that showed pulses of both ovarian oxytocin and PGFM was significantly $(P<0.05)$ greater in progesterone-treated ewes than in control ewes. In progesterone-treated ewes, the average number of ovarian oxytocin pulses per ewe was $9.66 \pm 5.5$ (mean $\pm \mathrm{SD}$ ) and the interval between pulses was $7.18 \pm 5.8 \mathrm{~h}$. The mean amplitude and amount of oxytocin released, as calculated by the area under the curve of ovarian oxytocin pulses, were $6.27 \pm 1.98 \mathrm{ng}$ $\min ^{-1}$ and $\left(10.05 \pm 8.91 \mathrm{ng} \mathrm{min}^{-1}\right) \tau$, respectively (where $\tau$ is the number of hours between the last time point before and the first time point after a significant increase in hormone concentration was detected by the Pulsar program). The mean amplitude and area under the curve of PGFM pulses were $317.22 \pm 5.65 \mathrm{pg} \mathrm{ml}^{-1}$ and $\left(383.36 \pm 1.77 \mathrm{pg} \mathrm{ml}^{-1}\right) \tau$, respectively. The average number of pulses of plasma PGFM observed per ewe was $5.8 \pm 1.9$ and interpulse interval for plasma PGFM pulses was $10.32 \pm 8.7 \mathrm{~h}$ between day 7 and day 9 after oestrus. These data indicate that administration of progesterone during the first 3 days of the oestrous cycle results in the premature release of ovarian oxytocin and uterine prostaglandin $\mathrm{F}_{2 u}$.
\end{abstract}

\section{Introduction}

Administration of progesterone early in the oestrous cycle of ewes (Ginther, 1968, 1969; Ottobre et al., 1980; Lawson and Cahill 1983) and cows (Ginther, 1970; Garrett et al., 1988) shortens the inter-oestrous interval by stimulating the earlier release of prostaglandin (PG) $F_{2 u}$ from the uterine endometrium which is responsible for the premature regression of the corpus luteum (Ginther, 1970; Ottobre et al., 1980; Garrett et al., 1988). Moreover, removal of a uterine horn adjacent to the luteal ovary (Ginther, 1968; Woody and Ginther, 1986) or infusion of indomethacin, an inhibitor of the synthesis of prostaglandins, into the uterine horn adjacent to the luteal ovary from day 8 to

Received 22 May 1997 day 11 prevents premature luteal regression after treatment with progesterone (Lewis et al., 1977).

Ovarian oxytocin also plays an important role in luteal regression in ewes by stimulating the secretion of the uterine luteolytic factor, $\mathrm{PGF}_{2 \alpha}$ (Fairclough et al., 1980, 1984; Flint and Sheldrick, 1983; Hooper et al., 1986; Moore et al., 1986) during the later stages of luteolysis. The ability of oxytocin to stimulate uterine $\mathrm{PGF}_{2 \alpha}$ secretion also depends on exposure to progesterone during the luteal phase of the cycle. Homanics and Silvia (1988) demonstrated that oxytocin can stimulate uterine secretion of prostaglandin $\mathrm{F}_{2 \alpha}$ in ovariectomized ewes after the animals have been exposed to progesterone for 7-10 days. Conversely, the release of the prostaglandin $\mathrm{F}_{2 \alpha}$ metabolite 13,14-dihydro-15-keto PGF $_{2 \alpha}$ (PGFM) on days 12-15 of the oestrous cycle, after an oxytocin challenge on day 12, was prevented in ewes treated with the progesterone receptor 
antagonist mifepristone (RU 486) in the early to mid-luteal phase of the oestrous cycle (Thomas et al., 1985; Morgan et al., 1993).

Whether premature $\mathrm{PGF}_{2 \alpha}$ release in response to early progesterone administration is due to a direct effect on the uterine $\mathrm{PGF}_{2 u}$ secretory system or is caused indirectly through the release of ovarian oxytocin is still uncertain. The aim of the present study was to determine whether $\mathrm{PGF}_{2 u}$ is released prematurely in response to early progesterone administration and, if so, whether such release is mediated via the premature release of ovarian oxytocin.

\section{Materials and Methods}

\section{Animal husbandry}

All protocols were approved by the Animal Experimentation Ethics Committees of Victoria University of Technology (AEEC 95/025) and CSIRO (Division of Animal Production).

Twelve, Border Leicester Merino cross ewes underwent ovarian auto-transplantation as described by Goding et al. (1967). Briefly, the right ovary was removed and the left ovary and its vascular pedicle were auto-transplanted into a jugularcarotid neck loop. The ovarian artery and the utero-ovarian vein were then anastomosed to the carotid artery and the jugular vein, respectively. During blood sampling, the ewes were housed individually in metabolism cages in a temperature-controlled room at $20^{\circ} \mathrm{C}$ and fed a ration of $800 \mathrm{~g}$ of pelleted food consisting of hammer-milled lucerne $(60 \%)$ and oats $(40 \%)$ once a day.

\section{Experimental protocol}

Ewes with auto-transplanted ovaries are not naturally cyclic. Therefore, oestrus was induced synchronously in the transplanted ewes by three i.m. injections of $125 \mu \mathrm{g}$ synthetic PGF $_{2 u}$ (Estrumate; ICI Pty Ltd, Sydney, NSW) given 15 days apart. After the third injection, oestrus was detected by inspection of the ewes twice a day for the presence of crayon marks after mating with a ram fitted with a sire-o-sine harness (Radford et al., 1960). The day that the ewe displayed oestrous behaviour was designated day 0 . The twelve ovarian autotransplanted ewes ( $n=6$ per group) were randomly assigned to receive an i.m. injection of $12.5 \mathrm{mg}$ progesterone in $1 \mathrm{ml}$ peanut oil (progestin; Intervet Pty Ltd, Sydney, NSW) or vehicle, twice a day, at intervals of 12 h, on days 1, 2 and 3 of the induced oestrous cycle.

\section{Cannulation of ovarian and jugular veins}

Cannulation of blood vessels was performed as described by Downing (1994) at least $12 \mathrm{~h}$ before the start of blood sampling. Briefly, cannulation was performed under local anaesthesia (10\% lignocaine hydrochloride spray: xylocaine; Astra Pharmaceuticals, Sydney, NSW). The ovarian vein was cannulated by inserting a polyvinyl catheter into the jugular vein exteriorised in the skin loop, using a $12 \mathrm{G}$ hypodermic needle as a trocar. The tip of the catheter was positioned at the junction of the ovarian and jugular veins. An additional polyvinyl catheter $(50 \mathrm{~cm})$ was inserted into the contralateral jugular vein to a distance of $10 \mathrm{~cm}$. The free ends of both catheters were fitted with a blunted $19 \mathrm{G}$ needle and connected to a three-way stopcock. The catheters were secured by suturing to the skin and wrapping elastoplast strips around the tubing at the site where it entered the neck. The catheters were filled with heparinized saline (1000 iu $\mathrm{ml}^{-1}$ ).

\section{Blood sampling}

Blood samples $(1.5 \mathrm{ml})$ were collected from the contralateral jugular vein at intervals of $\mathrm{I} \mathrm{h}$ for $70 \mathrm{~h}$ starting on day 7 after oestrus. Blood was centrifuged at $1900 \mathrm{~g}$ for $15 \mathrm{~min}$ and the plasma collected and stored at $-20^{\circ} \mathrm{C}$ until assayed for PGFM and progesterone concentrations. The procedure used for blood sampling was as follows: the heparinized saline was first removed from the contralateral jugular catheter and collected into a syringe fitted to the three-way stopcock connected to the catheter. The blood sample was then taken and placed in a heparinized glass tube and the catheter refilled with heparinized saline (50 iu $\mathrm{ml}^{-1}$ ).

Ovarian venous blood $(2 \mathrm{ml})$ was collected at the same time using the method described by Downing (1994). Briefly, the ewe was restrained to the side of the metabolism cage using a halter. A sphygmomanometer cuff was placed on the upper part of the skin loop and inflated above maximum venous pressure to obstruct the carotid artery and jugular vein. The forefinger and thumb were used to occlude the jugular vein in the lower part of the skin loop. The blood sample was then taken as described above. Every $4 \mathrm{~h}$, samples of ovarian venous blood (approximately $5 \mathrm{ml}$ ) were taken instead of the $2 \mathrm{ml}$ ovarian venous samples but following the same procedure. These samples were collected into heparinized $15 \mathrm{ml}$ graduated centrifuge tubes after clearing the ovarian/jugular vein catheter of heparinized saline and allowing around 10 drops of ovarian venous blood to pass through the stopcock. The time taken to collect this sample was measured using a stopwatch.

Blood flow ( $\mathrm{ml} \mathrm{min}^{-1}$ ) was calculated from the time required to collect a known volume of ovarian venous blood. The packed cell volume ( $\mathrm{PCV}$ ) was determined for each timed ovarian sample and the plasma flow $\left(\mathrm{ml} \mathrm{min}^{-1}\right)$ was calculated by multiplying the blood flow by (100-PCV) divided by 100 . Ovarian blood samples were assayed for oxytocin, and the secretion rate of oxytocin ( $\mathrm{ng} \mathrm{min}^{-1}$ ) was obtained by multiplying the plasma flow ( $\mathrm{ml} \mathrm{min}^{-1}$ ) by the concentration of oxytocin in the ovarian venous plasma ( $\mathrm{ng} \mathrm{ml}^{-1}$ ).

\section{Hormonal analysis}

PGFM assay. Plasma PGFM concentrations were measured by radioimmunoassay as described by Burgess et al. (1990). The antiserum was raised in sheep against PGFM conjugated to porcine gelatine and was kindly supplied by R. I. Cox (CSIRO, Blacktown, NSW). At a final dilution of 1:50 000, the crossreactivity of this antiserum with 13,14 -dihydro-15-keto-PGF $2{u^{\prime}}$ 6,15-diketo-13,14, dihydro PGF $1 \alpha^{\prime} 13,14$ dihydro-15-keto-PGE ${ }_{2}$, 15-keto-PGF $2 u^{\prime}$ 15-keto-PGE 2 and PGA $_{2}$ was 100, 4.6, 1.9, $0.94,0.33$ and $0.02 \%$, respectively, and was $<0.01 \%$ with 
$\mathrm{PGF}_{2 \alpha^{\prime}} \mathrm{PGE}_{2}$, 6-keto-PGF $1 \mathrm{P}$, 6-keto-PGE $1, \mathrm{PGE}_{1}, \mathrm{PGD}_{2}, \mathrm{PGB}_{2}$ and thromboxane $B_{2}$. The sensitivity of the assay was $0.022 \mathrm{pmol}$ per $200 \mu \mathrm{l}$. The intra- and interassay coefficients of variation were $9.35 \%$ and $10.4 \%$, respectively.

Progesterone assay. For the progesterone assay, $200 \mu \mathrm{l}$ of jugular venous plasma was extracted with $2 \mathrm{ml} n$-hexane as described by Rice et al. (1986). The antiserum was raised in sheep against progesterone-II $\alpha$-BSA (generously provided by J. Malecki, Regional Veterinary Institute, Department of Agricultural and Rural Affairs, Bairnsdale, Victoria). At a final dilution of $1: 9000$, the crossreactivity of the antiserum with progesterone, II $\alpha$-hydroxy-progesterone, $5 \alpha$-pregnane- $3 \alpha$ ol,20-one, $5 \beta$-pregnane-3 $\alpha$-ol,20-one and corticosterone was $100,43.8,15.9,10.0$ and $1.05 \%$, respectively. Crossreactivity was $<1.0 \%$ with 11 -deoxycortisol, $5 \alpha$-pregnane- $3 \alpha, 17 \alpha$-diol20-one, $5 \beta$-pregnane-3 $\alpha, 17 \alpha, 20 \alpha$-triol-20-one, $5 \beta$-pregnane$3 \alpha, 17 \alpha, 20 \alpha$-triol and $5 \alpha$-pregnane-3 $\beta$-ol-2-one, $0.70 \%$ with $17 \alpha$-hydroxy-progesterone, $<0.4 \%$ with dehydroepiandrosterone, $0.3 \%$ with $20 \alpha$-hydroxy-pregnene 3 -one and $<0.2 \%$ with cortisol. The sensitivity of the assay was $0.22 \mathrm{pmol}$ per $200 \mu \mathrm{l}$. All samples were measured in one assay and the intra-assay coefficient of variation was $16.5 \%$.

Oxytocin assay. For the assay of oxytocin, $300 \mu \mathrm{l}$ of the standards or ovarian plasma samples were mixed with $3 \mathrm{ml}$ of chilled $\left(-20^{\circ} \mathrm{C}\right)$ absolute ethanol using a modification of the method described in the Australian Laboratory Services Oxytocin Radioimmunoassay Kit. After centrifugation at $1900 \mathrm{~g}$ for $20 \mathrm{~min}$ at $4^{\circ} \mathrm{C}$, the supernatant was decanted and evaporated to dryness with filtered air at $37^{\circ} \mathrm{C}$ using a sample concentrator. The residues of these solutions were reconstituted in $300 \mu \mathrm{l}$ of $0.05 \mathrm{~mol}$ phosphate buffer $\mathrm{I}^{-1}(\mathrm{pH} 7.4)$. Standards and samples were incubated for at least $30 \mathrm{~min}$ at $4^{\circ} \mathrm{C}$. One hundred microlitres of ${ }^{125} \mathrm{I}$ tracer (10 000 c.p.m., Du Pont, Melbourne, Vic) was added to duplicate aliquots of $100 \mu \mathrm{l}$ of extracted standards and samples, followed by $100 \mu \mathrm{l}$ of antisera diluted in assay buffer. The assay was incubated overnight at $4^{\circ} \mathrm{C}$. Separation of the bound oxytocin was achieved by the addition of $0.05 \mathrm{ml}$ ( $1 \mathrm{mg}$ ) bovine immunoglobulin serum (Calbiochem, Sydney, NSW) and $1 \mathrm{ml}$ of $15 \%$ polyethylene glycol 6000 (Crown Scientific, Melbourne, Vic) at $4^{\circ} \mathrm{C}$ and then centrifuged at $3300 \mathrm{~g}$ for $20 \mathrm{~min}$. The supernatant was aspirated and the radioactivity present in the precipitate was quantified using a Packard Crystal GammaCounter. The antiserum to oxytocin (GJ, 137/1), was raised in sheep and was kindly donated by A. P. F. Flint (University of Nottingham, Sutton Bonington, Notts) and was used at a final dilution of 1:37 000. The crossreactivity of this antiserum with oxytocin, isotocin and melanocyte-stimulating hormone was $100,0.79$ and $0.04 \%$, respectively. The crossreactivity was $<0.02 \%$ with mesotocin, pressinoic acid, prolactin, argininevasopressin and lysine-vasopressin. The sensitivity of the assay was $1.1 \mathrm{pg}$ per $100 \mu \mathrm{l}$, the intra- and interassay coefficients of variation were $11.80 \%$ and $14.48 \%$, respectively.

\section{Statistical analyses}

Pulses of ovarian vein oxytocin and jugular PGFM that were statistically significant were identified using a Pulsar program
(Merriam and Wachter, 1982). Assay noise was estimated by regression analysis of the standard deviation for the duplicate determinations and the mean at each point. Baseline was calculated from the contribution of circadian rhythms or other longterm trends, but not from fluctuations of shorter duration. The amplitudes of the ovarian oxytocin and peripheral PGFM pulses were calculated by subtracting baseline values and then rescaling in terms of SD units, by dividing the rescaled values by an estimate of assay noise. The amplitude in the rescaled pulses was then identified by applying height and duration criteria specified by user-defined cut-off points $[G(n)]$ for pulses. These calculations were repeated until two iterations produced the same values for pulses or until the preset limit of six iterations were completed. The quadratic $(a)$, linear $(b)$, and constant $(c)$ terms for pulsar were as follows: for oxytocin, $a=0.00, b=11.8, c=0.00$; and for PGFM, $a=0.00, b=9.35$, $c=0.00$. The $\mathrm{G}(n)$ values for pulses with $n=1,2,3,4$ or 5 points above the baseline were selected by an empirical approach using a selected data series for each hormone from one animal which was then applied to all animals in the study. The following $G(n)$ values were selected for oxytocin pulses: $\mathrm{G}(1)=6.0, \mathrm{G}(2)=4.1, \mathrm{G}(3)=3.0, \mathrm{G}(4)=2.37, \mathrm{G}(5)=1.89$; and for PGFM pulses: $\mathrm{G}(1)=7.1, \mathrm{G}(2)=6.5, \mathrm{G}(3)=3.8, \mathrm{G}(4)=3.0$, $G(5)=2.4$. The values reported for intervals between ovarian oxytocin and peripheral PGFM pulses were determined by calculating the time that elapsed between the highest values of sequential pulses. Coincident episodes in the secretion of oxytocin and PGFM were defined as those that showed an increase in the value of the PGFM pulse coincident with a defined oxytocin pulse. The plasma secretion rates of oxytocin and concentrations of PGFM pulses were determined as ng $\min ^{-1}$ and $\mathrm{pg} \mathrm{ml}{ }^{-1}$, respectively, while the duration of that pulse was designated as $\tau$, being the number of hours between the last time point before and the first time point after a significant increase in hormone concentration was detected by the Pulsar program. The areas under the curve of significant ovarian oxytocin and peripheral PGFM pulses were calculated for each ewe and were expressed as $\left(\mathrm{ng} \mathrm{min}^{-1}\right) \tau$ and (pg $\mathrm{ml}$

$\left.{ }^{-1}\right) \tau$, respectively. Estimated parameters included overall mean concentrations, basal value, number of pulses, pulse amplitude, area under curve for the pulse and inter-pulse interval, and were carried out using the Pulsar analysis program.

The number of ewes that showed episodic pulses of oxytocin and PGFM were compared using a Chi-Squared test. The mean $( \pm \mathrm{SD}$ ) concentrations of progesterone, basal oxytocin and PGFM between experimental and control animals were compared using Student's unpaired $t$ test.

\section{Results}

The concentration of progesterone in the peripheral plasma of the control ewes during the sampling period was $2.11 \pm 0.62 \mathrm{ng} \mathrm{ml}^{-1}$ (mean $\pm \mathrm{SD}$ ) which was not significantly different $(P>0.05)$ from that of progesterone-treated ewes; $2.32 \pm 0.90 \mathrm{ng} \mathrm{ml}^{-1}$. Progesterone concentrations remained raised during the sampling period, indicating the presence of a functional corpus luteum in both groups (Figs 1 and 2).

The basal secretion rate of ovarian oxytocin for ewes treated with progesterone early in the cycle $\left(1.77 \pm 1.56 \mathrm{ng} \mathrm{min}^{-1}\right)$ 
(a)

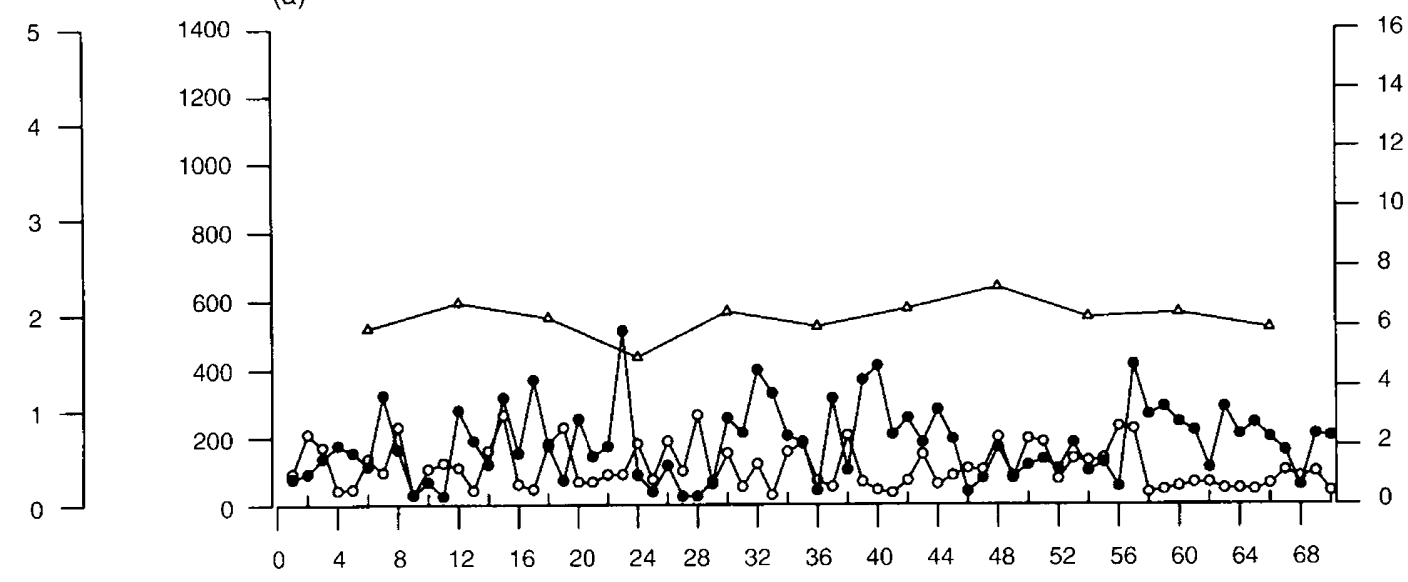

(b)

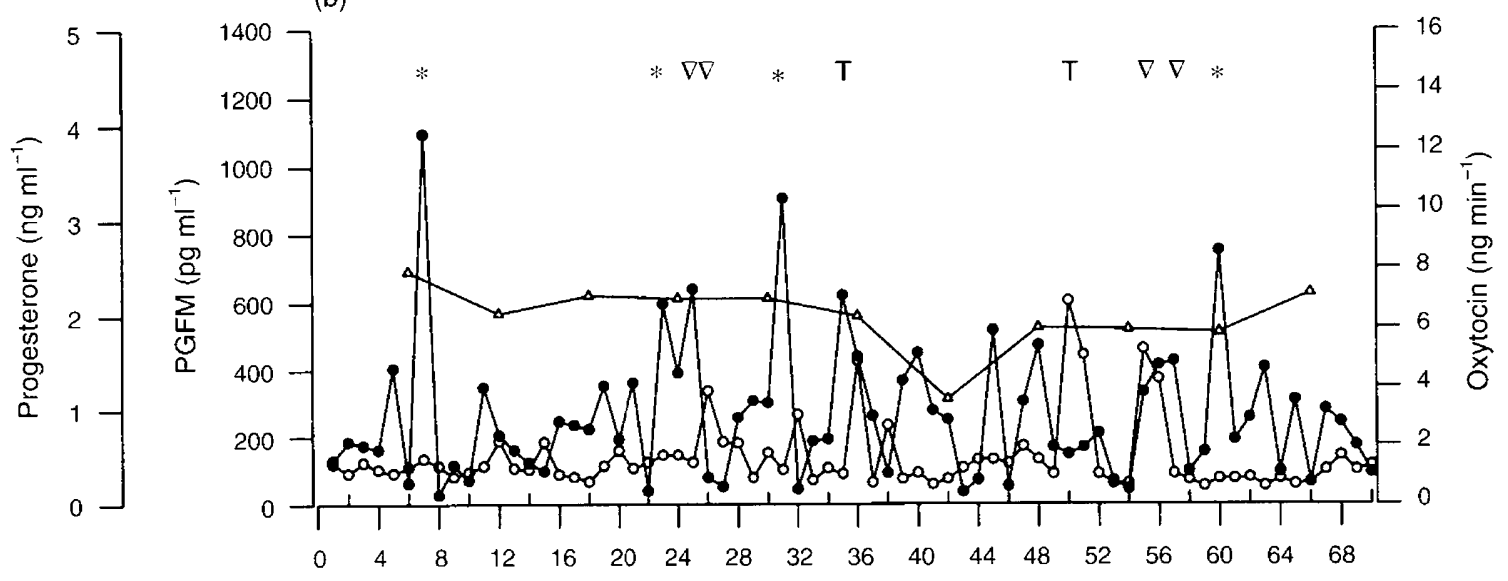

(c)

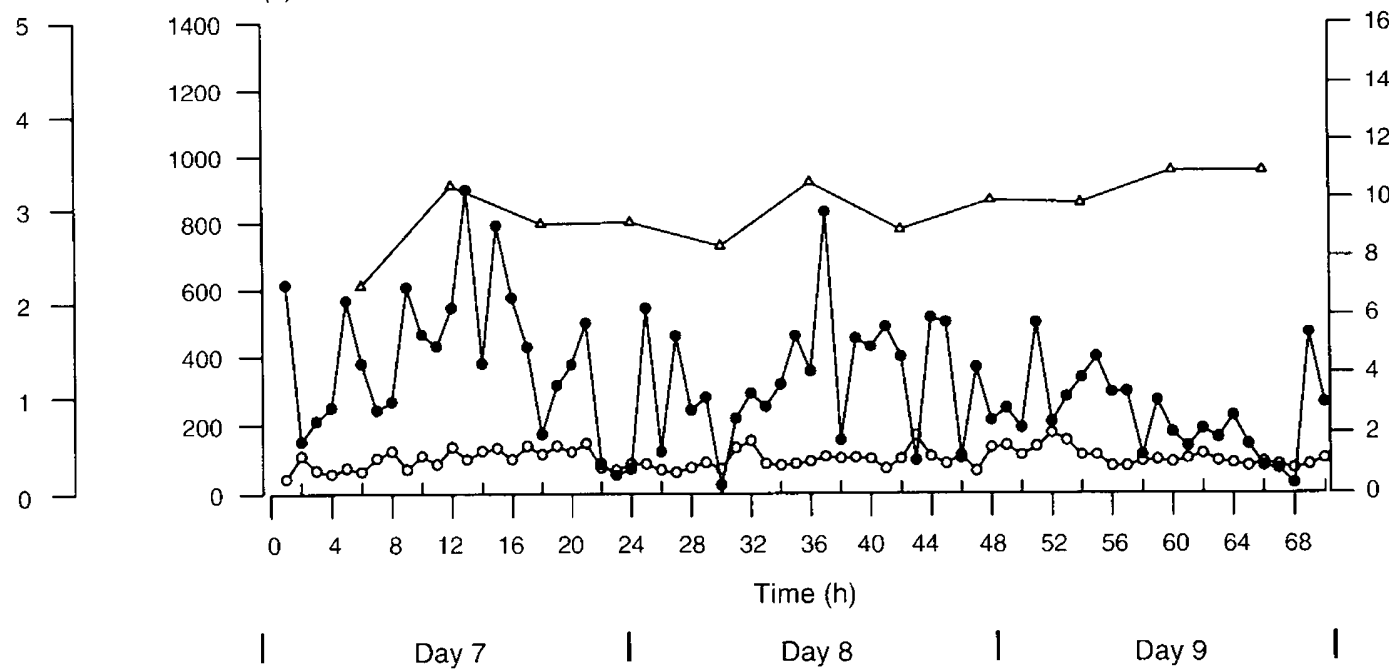

Fig. 1. (a)-(c).

was not significantly $(P>0.05)$ different from that in control ewes $\left(2.41 \pm 0.57 \mathrm{ng} \mathrm{min}^{-1}\right)$. Administration of progesterone during the first 3 days of the cycle resulted in a significant $(P<0.05)$ increase in the number of treated ewes showing pulses of both oxytocin ( $n=6$ versus $n=2)$ and PGFM $(n=5$ versus $n=1$ ) when compared with the control ewes. There was also an increase in the number of oxytocin pulses in ovarian venous plasma and PGFM pulses in peripheral plasma over days 7-9 after oestrus when compared with control ewes (58 versus 10 and 29 versus 4 , respectively). The average 
(d)

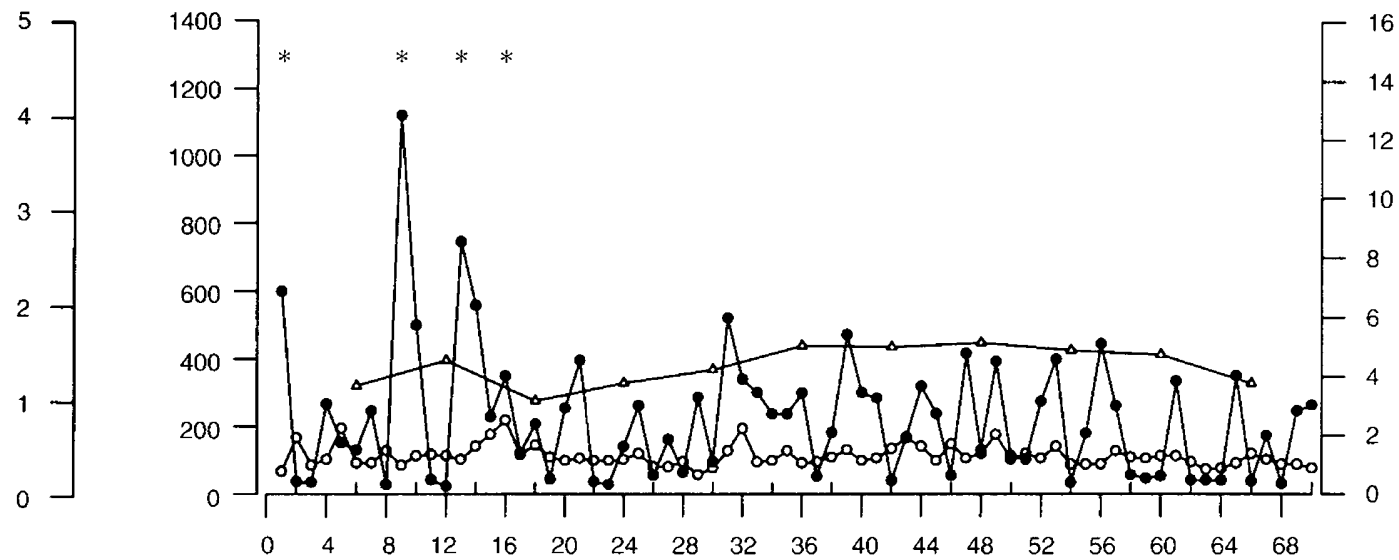

(e)
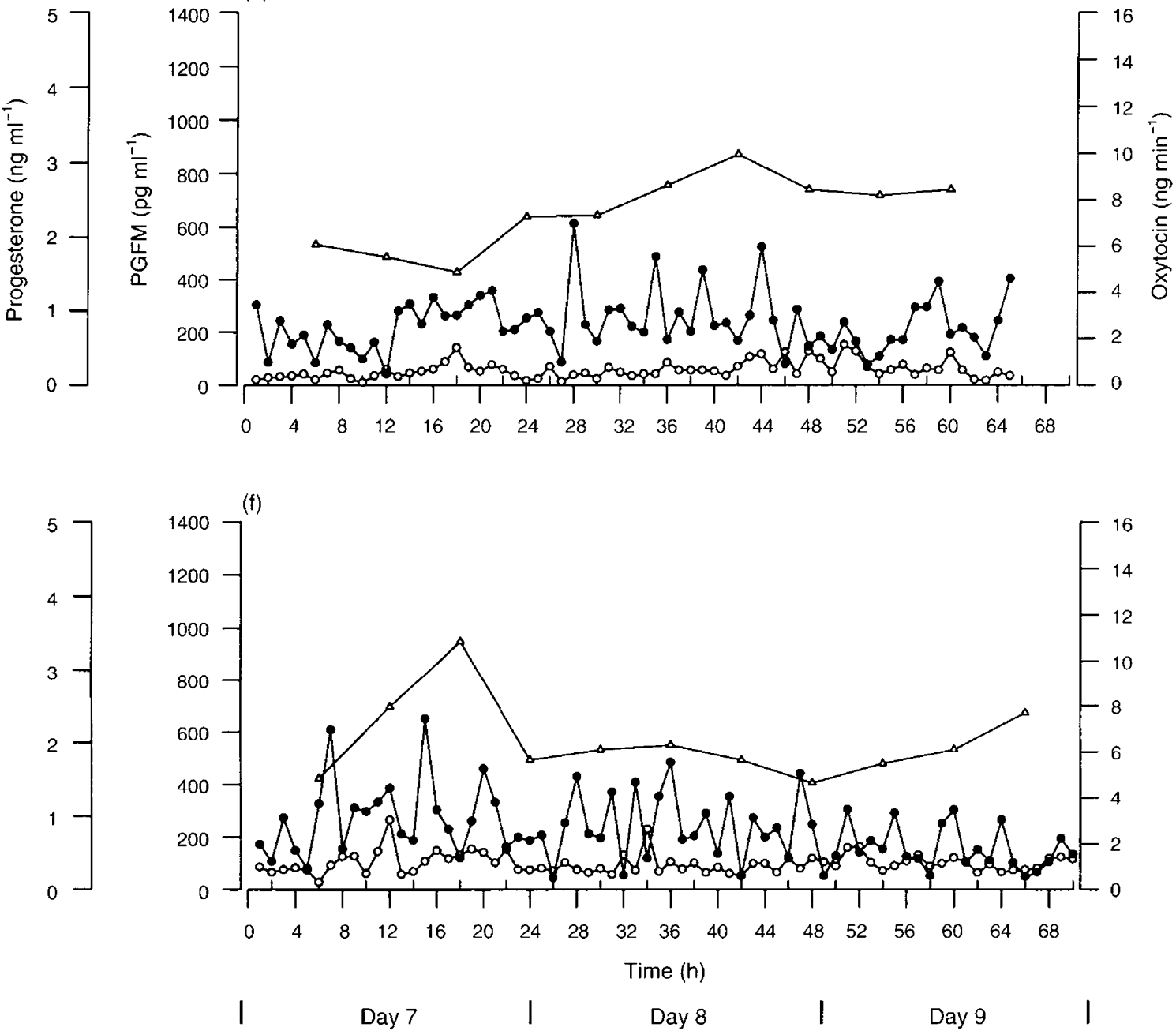

Fig. 1. (d) $-(\mathrm{f})$.

Fig. 1. The effect of vehicle injections during the first 3 days of the oestrous cycle on $(\bullet)$ oxytocin secretion in ovarian venous plasma and concentrations of ( ) the prostaglandin $\mathrm{F}_{2,1}$ metabolite 13,14-dihydro-15-keto PGF 20 (PGFM) and ( $)$ progesterone in peripheral plasma from individual ewes with an auto-transplanted ovary (a-f), on days 7,8 and 9 after oestrus. Statistically significant episodes in the secretion of ovarian oxytocin and PGFM are indicated by $(*)$ and $(T)$, respectively. (unchronous episodes of secretion of both compounds. 
(a)
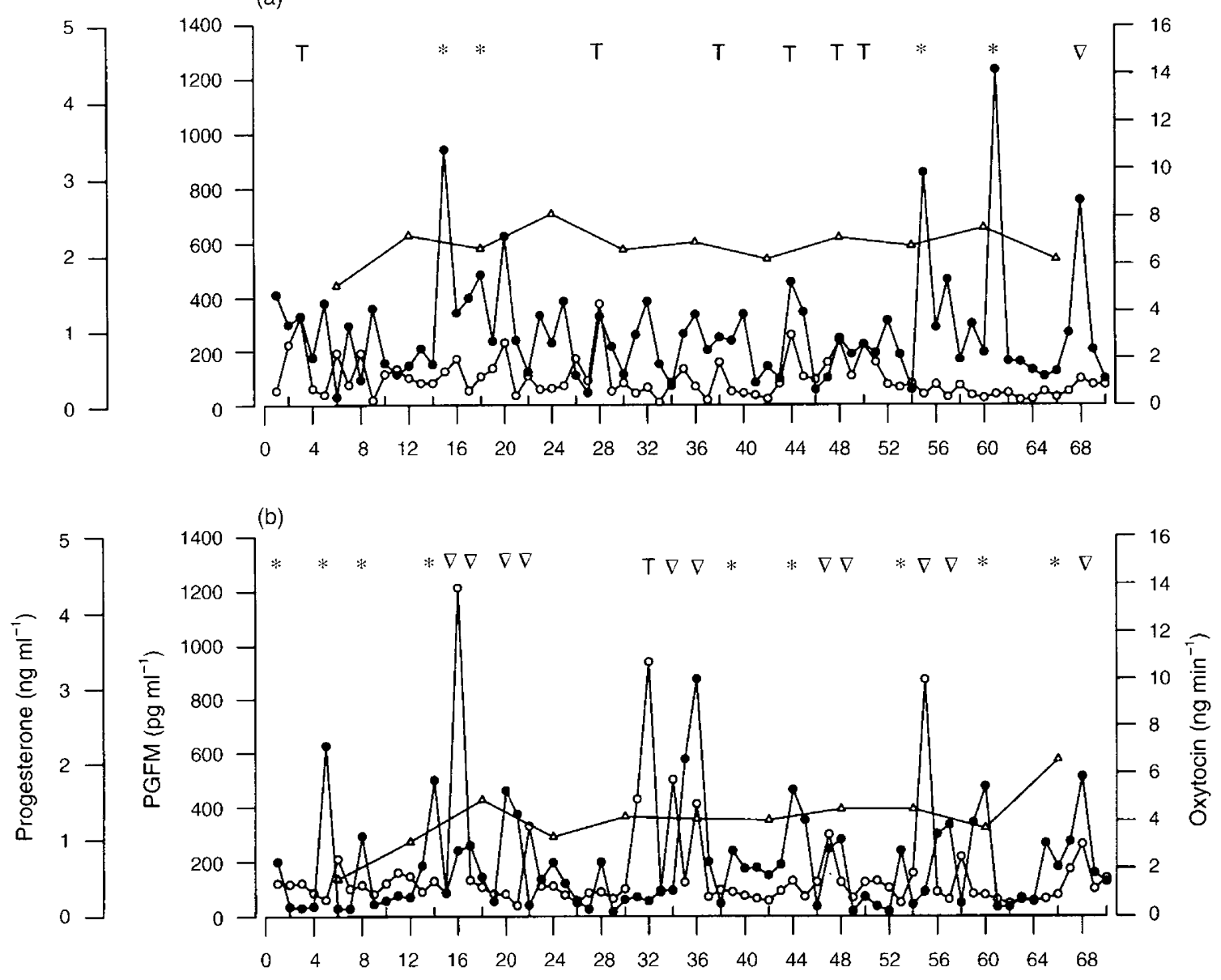

(c)

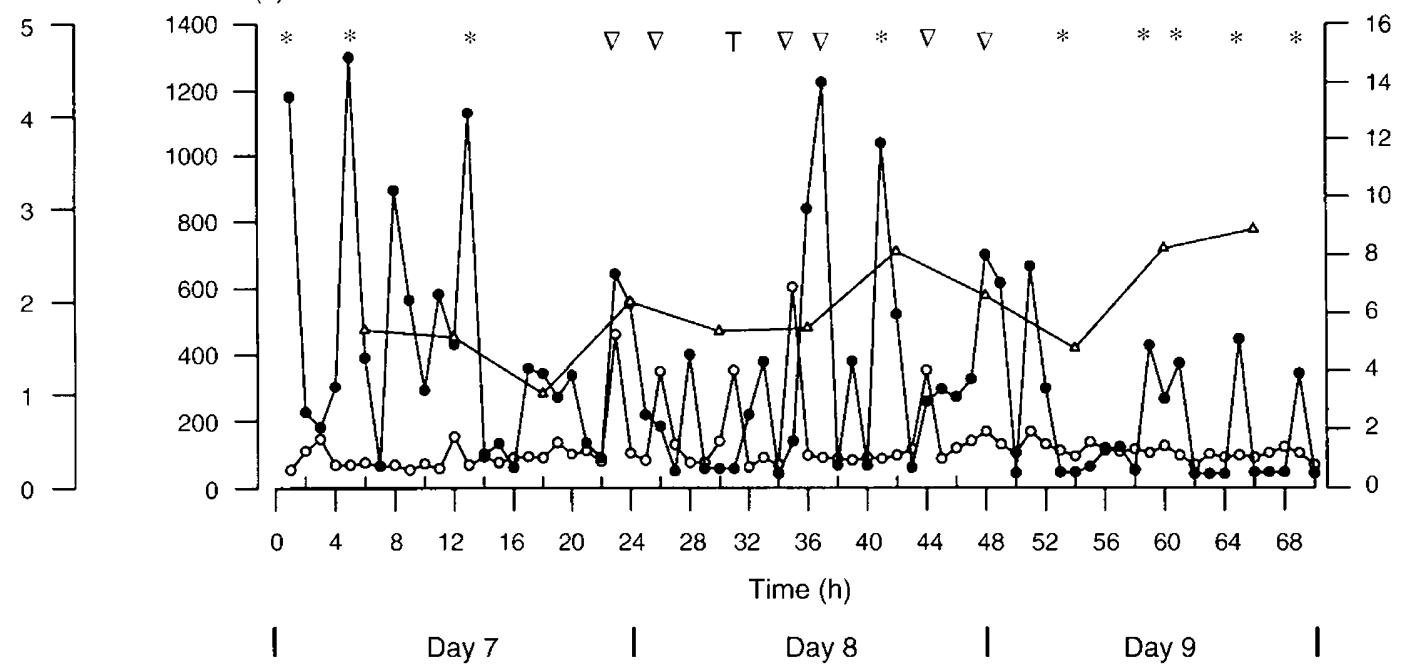

Fig. 2. (a)-(c).

number of pulses of oxytocin per ewe was $9.66 \pm 5.5$ and the interpulse-interval was $7.18 \pm 5.78 \mathrm{~h} \mathrm{(Fig.} \mathrm{2)} \mathrm{in} \mathrm{the}$ progesterone-treated ewes. The mean amplitude and area under the curve for ovarian oxytocin pulses were $6.27 \pm 1.98 \mathrm{ng}$ $\min ^{-1}$ and (10.05 $\left.\pm 8.91 \mathrm{ng} \min ^{-1}\right) \tau$, respectively. In four of the six control ewes, no detectable pulse of ovarian oxytocin was found during days 7,8 or 9 of the oestrous cycle. In one of the other two control ewes, four pulses of ovarian oxytocin were observed (Fig. Id) at the start of blood sampling, with an average amplitude of $6.66 \pm 3.72 \mathrm{ng} \mathrm{min}^{-1}$. In the other ewe (Fig. Ib), there were six pulses of oxytocin in ovarian venous plasma. The mean amplitude and the area under the curve for 
(d)

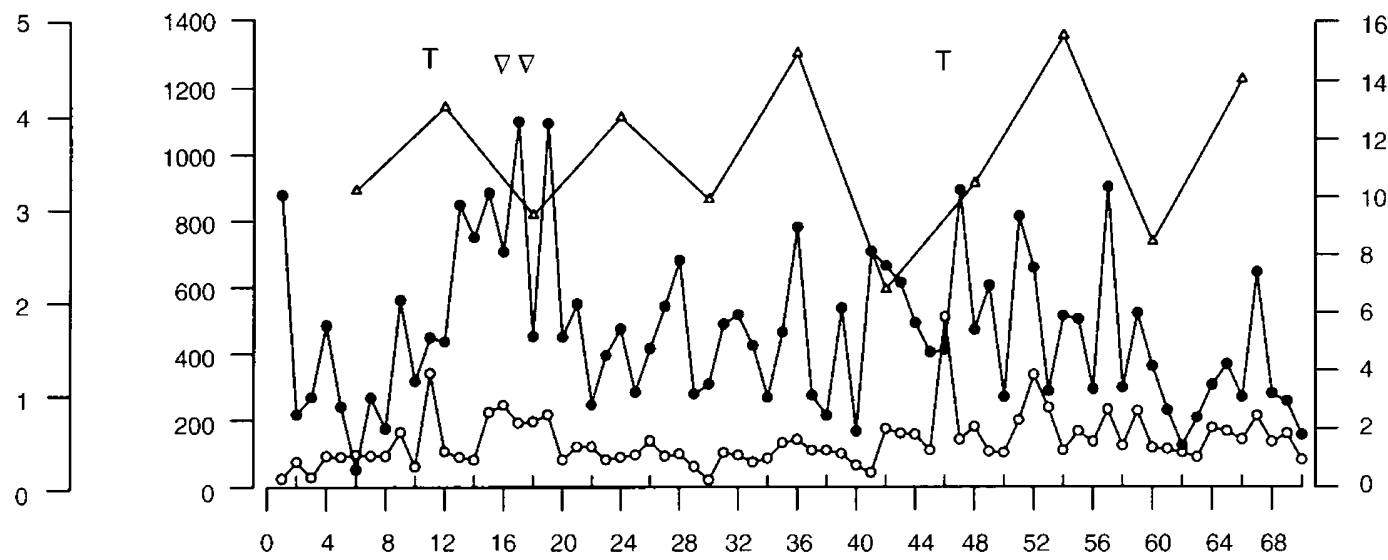

(e)

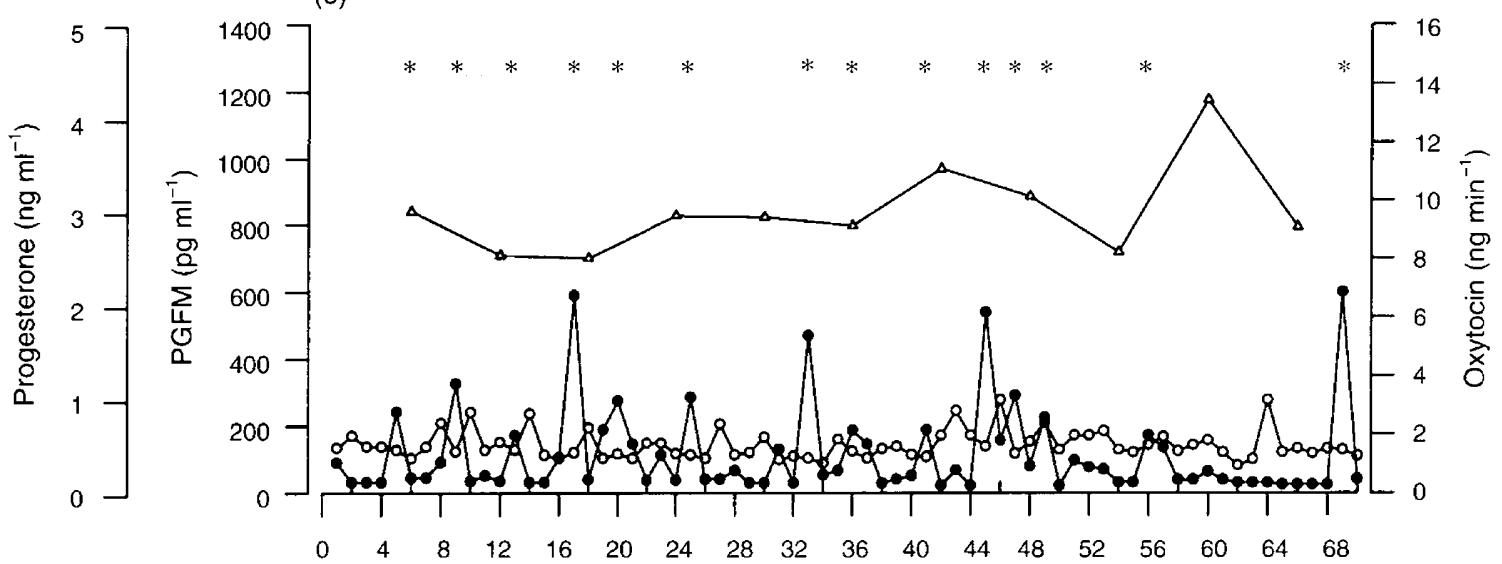

(f)

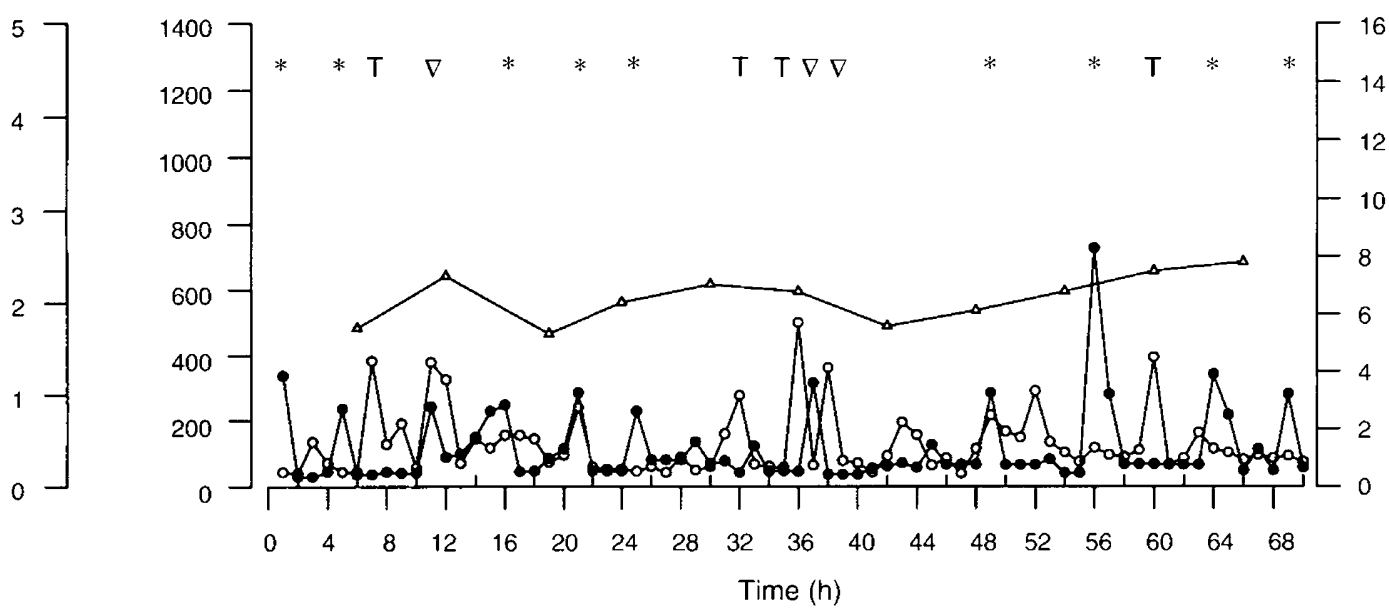

$\begin{array}{llllll}\text { I Day } 7 & \text { I } & \text { Day } 8 & \text { Day } 9 & \text { I }\end{array}$

Fig. 2. (d)-(f).

Fig. 2. The effect of progesterone injections during the first 3 days of the oestrous cycle on $(\bullet)$ oxytocin secretion in ovarian venous plasma and concentrations of (0) the prostaglandin $\mathrm{F}_{2 u}$ metabolite 13,14-dihydro-15-keto PGF $_{2 u}$ (PGFM) and () progesterone in peripheral plasma from individual ewes with an auto-transplanted ovary (a-f), on days 7,8 and 9 after oestrus. Statistically significant episodes in the secretion of ovarian oxytocin and PGFM are indicated by (*) and (T), respectively. (v) synchronous episodes of secretion of both compounds. 
ovarian oxytocin pulses for this ewe were $6.14 \pm 2.79 \mathrm{ng}$ $\min ^{-1}$ and $\left(5.22 \pm 1.44 \mathrm{ng} \mathrm{min}^{-1}\right) \tau$, respectively.

In five of six ewes given progesterone, at least one defectable pulse in plasma PGFM concentration was observed during the sampling period. In these ewes, the mean amplitude and area under the curve for PGFM pulses were $317.22 \pm 145.65 \mathrm{pg} \mathrm{ml}^{-1}$ and $\left(383.36 \pm 111.77 \mathrm{pg} \mathrm{ml}^{-1}\right) \tau$, respectively. The average number of PGFM pulses observed per ewe was $5.8 \pm 1.9$ and sequential pulses of PGFM occurred at an average of $10.32 \pm 8.7 \mathrm{~h}$ intervals between day 7 and day 9. In one of the progesterone-treated ewes (Fig. 2e) pulses of oxytocin were observed without a corresponding increase in plasma PGFM concentrations (maximum $276.5 \mathrm{pg} \mathrm{ml}^{-1}$ ). Basal peripheral plasma concentrations of PGFM for ewes treated with progesterone early in the cycle $\left(97.43 \pm 22.92 \mathrm{pg} \mathrm{ml}^{-1}\right)$ were not significantly $(P>0.05)$ different from those in control ewes $\left(91.32 \pm 20.65 \mathrm{pg} \mathrm{ml}^{-1}\right)$. No significant pulses in plasma PGFM concentrations were found in the vehicle-treated ewes apart from in one ewe (Fig. 1b). In this ewe, four pulses of PGFM were observed in peripheral plasma with an average amplitude of $359.08 \pm 118.14 \mathrm{pg} \mathrm{ml}^{-1}$. The average area under the curve for PGFM pulses for this ewe was $\left(555.61 \pm 251.98 \mathrm{pg} \mathrm{ml}^{-1}\right) \tau$.

In ewes that received progesterone early in the cycle, there were at least twice as many oxytocin pulses compared with PGFM pulses, and at least half (51.7\%) of the plasma PGFM pulses occurred coincidently with a significant increase in ovarian oxytocin. In contrast, only $22.4 \%$ of ovarian oxytocin pulses were coincident with, or preceded, pulses of plasma PGFM concentrations.

\section{Discussion}

In the current study, the ovarian auto-transplanted ewe was used as a model to determine the secretion rate of ovarian oxytocin and peripheral plasma concentrations of PGFM and progesterone in ewes given progesterone early in the oestrous cycle.

Hooper et al. (1986) reported that the concentration of oxytocin in peripheral plasma ranged from 20 to $220 \mathrm{pg} \mathrm{ml}^{-1}$ until day 9 after oestrus and was much lower than those in utero-ovarian venous plasma $\left(230-1020 \mathrm{pg} \mathrm{ml}^{-1}\right)$. Concentrations of oxytocin in ovarian venous plasma detected in the present study were $440-1430 \mathrm{pg} \mathrm{ml}^{-1}$ which are similar to those detected by Hooper et al. (1986) in the utero-ovarian vein (50-1499 $\mathrm{pg} \mathrm{m}^{-1}$ ) over days 13-16 after oestrus. These observations indicate that, in the current study, oxytocin in ovarian venous plasma represents luteal rather than posterior pituitary secretion.

Administration of progesterone from day 1 to day 3 of the oestrous cycle resulted in a significant increase in the number of ewes showing pulses of both oxytocin and PGFM. There was also an increase in the number of oxytocin pulses in ovarian venous plasma and PGFM pulses in peripheral plasma over days 7-9 after oestrus in the progesterone-treated ewes when compared with the vehicle-treated ewes. The effect of progesterone treatment on the pattern of plasma PGFM concentration is consistent with previous reports in ewes (Ottobre et al., 1980) and cows (Ginther, 1970; Garrett et al., 1988). The data reported in these previous studies indicated that treatment with progesterone early in the cycle at a dose equivalent to that used in the present study advanced the time at which PGF $2 a$ was released in intact animals and caused premature luteolysis. Previous reports had shown that uterine PGF $_{2 \alpha}$ acts on the adjacent ovaries in intact animals through a local pathway by counter-current transfer from the uterine vein to the ovarian artery (Barret ef al., 1971; McCracken et al., 1972) and causes regression of the corpus luteum. Uterine $\mathrm{PGF}_{2 \alpha}$ is cleared rapidly from the blood after one passage through the lungs as it is metabolized in the pulmonary vascular bed (Piper et al., 1970). The finding, in the study reported here, of intermittent pulses of PGFM, but an absence of luteolysis in ovarian auto-transplanted ewes, confirms previous views that uterine $\mathrm{PGF}_{2 \alpha}$ acts by a local counter-current mechanism to induce luteolysis in intact ewes (Barret et al., 1971; McCracken et al., 1972).

Peripheral progesterone concentrations are normally low ( $<1 \mathrm{ng} \mathrm{ml} \mathrm{m}^{-1}$ ) during the first 4 days of the oestrous cycle (Webb et al., 1981; Garrett et al., 1988) and administration of exogenous progesterone during days 1-4 after oestrus to cyclic cows increases peripheral plasma concentrations of progesterone during days $2-5$ after oestrus to concentrations comparable with those of control cows on day 5 to day 9 of the oestrous cycle (Garrett et al., 1988). In ewes, plasma progesterone concentrations normally start to fall on day 12 or day 13 after oestrus, or around the time of the first significant increase in the secretion of uterine $\mathrm{PGF}_{2 \alpha}$. This would indicate that $7-8$ days are required as a minimum exposure time of the uterus to progesterone before the uterus secretes PGF $_{2 \alpha}$ (Baird et al., 1976; Homanics and Silvia, 1988). Previous studies have suggested that the duration of exposure of the uterus to progesterone plays a key role in the regulation of the timing of the initial increases in the release of $\mathrm{PGF}_{2 \alpha}$ (Baird et al., 1976; Ottobre et al., 1980). The results of the present study give further support to this premise, since the administration of progesterone on days 1,2 and 3 of the oestrous cycle stimulated premature pulses of peripheral plasma PGFM secretion over days 7-9 after oestrus.

It is possible that progesterone also causes the premature release of uterine $\mathrm{PGF}_{2 u}$ through ovarian oxytocin release. It is now well accepted that, in intact ewes, ovarian oxytocin stimulates uterine $\mathrm{PGF}_{2 a}$ release during the late luteal phase of the oestrous cycle (Flint and Sheldrick, 1983; Hooper et al., 1986). The data obtained from the present study, therefore, raise the possibility that progesterone also acts to regulate the timing of the release of ovarian oxytocin, since the administration of progesterone to ewes early in the cycle resulted in a significant increase in the number of ewes that exhibited pulses of ovarian oxytocin compared with control ewes.

The results from the present study and other reports (Fairclough et al., 1980, 1983; Hooper et al., 1986) also show that oxytocin pulses in ovarian or utero-ovarian venous plasma, or oxytocin-neurophysin in jugular venous plasma frequently occur in the absence of any significant increase in utero-ovarian $\mathrm{PGF}_{2 a}$ or peripheral PGFM pulses, and indicates that ovarian oxytocin release can occur independently of uterine $\mathrm{PGF}_{2 \alpha}$ release. Furthermore, the largest number of pulses with maximum ovarian oxytocin secretion rate was observed on day 7 , whilst the largest number of pulses that 
occurred with maximum concentrations of plasma PGFM were observed on day 8 of the oestrous cycle. The study reported here and that of Hooper $\mathrm{et}$ al. (1986) have shown that pulses of uterine $\mathrm{PGF}_{2 \alpha}$ or PGFM occur without simultaneous pulses of oxytocin. One possible explanation for this observation is that progesterone acts, at least in part, directly on the uterus to stimulate uterine $\mathrm{PGF}_{2 \alpha}$ release. Alternatively, oxytocin pulses may have been missed in the present study because of the sampling schedule, or may not have been detected given the stringent criteria used to identify significant pulses by the Pulsar program.

Hooper et al. (1986) reported that, in ewes, $97 \%$ of all pulses of uterine $\mathrm{PGF}_{2 \alpha}$ release were accompanied or followed by pulses of oxytocin in the ovarian vein, while only $56 \%$ of oxytocin pulses were coincident with pulses in uterine $\mathrm{PGF}_{2 \alpha}$, The sampling frequency in the present study (every hour) resulted in a similar pattern, although in the present study, only $51.7 \%$ of plasma PGFM pulses were associated with pulses in ovarian oxytocin. This difference may be due to the different statistical criteria used to detect the significant pulses of oxytocin and PGFM. In addition, the interpulse interval was greater in the present study than in that of Hooper et al. (1986): oxytocin (1.6 \pm 0.94 versus $2.5 \pm 0.19$ ) and $\mathrm{PGF}_{2 \alpha}(1.0 \pm 0.3$ versus $1.3 \pm 0.2$ ) pulses per $12 \mathrm{~h}$. However, the area under the curve for ovarian oxytocin and PGFM pulses in the present study were higher and longer, covering more consecutive samples per pulse than in the study by Hooper et al. (1986). The observation showing several pulses in ovarian oxytocin without a corresponding increase in plasma PGFM concentrations could be due to uterine refractoriness to oxytocin at that time. Alternatively, it may reflect the variation in response, in individual animals, to progesterone treatment or to the oxytocin stimulus.

As indicated in previous studies, there is a significant effect of progesterone and oestradiol on the pattern of plasma PGFM release in response to oxytocin. These studies have shown that low progesterone and high oestradiol concentrations increase the plasma PGFM response to oxytocin on day 12 of a simulated oestrous cycle (Beard et al., 1994). Chronic treatment with progesterone also enhances uterine secretion of $\mathrm{PGF}_{2 \alpha}$ in response to an i.v. injection of oxytocin (Silvia and Homanics, 1988). The mechanism involved in the action of progesterone is unknown, although Eggleston ef al. (1990) reported that treatment of intact ewes with progesterone early in the cycle induced a premature increase in the expression of mRNA encoding uterine prostaglandin $\mathrm{H}$ endoperoxide synthase.

However, the mechanism(s) by which progesterone acts to regulate the luteolytic process in sheep in not fully understood. It has been suggested that oxytocin receptors play an important role in regulating the duration of the oestrous cycle in sheep (McCracken et al., 1984), possibly through the downregulation of progesterone receptors and consequently the diminished inhibition of endometrial oestrogen and oxytocin receptors (McCracken et al., 1984; Wathes and Hamon, 1993). There is considerable evidence to indicate that concentrations of uterine oxytocin receptors are regulated by circulating concentrations of the steroid hormones (McCracken et al., 1984; Sheldrick and Flint, 1985), with oestradiol acting to induce receptor formation and progesterone acting, early in the cycle, to inhibit oxytocin receptors. During the later stages of the oestrous cycle, progesterone appears to lose its inhibitory influence, possibly through downregulation of uterine progesterone receptors (Vallet et al., 1990; Zhang et al., 1992). It is also possible that, in the study reported here, early progesterone treatment stimulated uterine oxytocin receptor concentrations, since on some occasions there were coincident pulses of ovarian oxytocin and PGFM at a time when oxytocin does not usually stimulate uterine $\mathrm{PGF}_{2 \alpha}$ release (Fairclough et al., 1984).

The present study is the first to indicate that ovarian oxytocin secretion is stimulated by the administration of progesterone during the first 3 days of the oestrous cycle, thus, raising the possibility that, in intact ewes, progesterone may directly or indirectly regulate ovarian oxytocin and uterine $\mathrm{PGF}_{2 \alpha}$ secretion systems and thus, the timing of luteal regression.

This project was supported by The Australian Research Council. The authors thank B. Gordon (CSIRO) for technical help and support in this study, M. Mohideen and J. Pergadis for their assistance in the collection of blood samples and J. Marry for technical assistance.

\section{References}

Baird DT, Land RB, Scaramuzzi RJ and Wheeler AG (1976) Endocrine changes associated with luteal regression in the ewe; the secretion of oestradiol, progesterone, androstenedione and uterine prostaglandin $\mathrm{F}_{21 t}$ throughout the oestrous cycle Journal of Endocrinology 69 275-286

Barret S, Blockey DeB, Brown JM, Cumming IA, Goding JR, Mole BJ and Obst JM (1971) Initiation of the oestrous cycle in the ewe by infusion of PGF 2 to the auto-transplanted ovary Journal of Reproduction and Fertility 4 136-137

Beard AP, Hunter MG and Lamming GE (1994) Quantitative control of oxytocin-induced $\mathrm{PGF}_{2 u}$ release by progesterone and oestradiol in ewes Journal of Reproduction and Fertility 100 143-150

Burgess KM, Ralph MM, Jenkin G and Thorburn GD (1990) Effect of oxytocin and oestradiol on uterine prostaglandin release in non-pregnant and early pregnant ewes Biology of Reproduction 42 822-833

Downing JA (1994) Interactions of Nutrition and Ovulation Rate in Ewes PhD Thesis, Macquarie University, NSW

Eggleston DL, Wilken C, Van Kirk EA, Slaughter RG and Murdoch WJ (1990) Progesterone induces expression of endometrial mRNA encoding for cyclooxygenase (sheep) Prostaglandins 39 675-683

Fairclough RJ, Moore LG and McGowan LT (1980) Temporal relationship between plasma concentrations of 13,14-dihydro-15-keto-prostaglandin $F$ and neurophysin I/II around luteolysis in sheep Prostaglandins 20 199-208

Fairclough RJ, Moore LG, McGowan LT, Smith JF and Watkens WB (1983) Effect of exogenous progesterone on plasma concentrations of the oxytocin associated neurophysin and 13,14-dihydro-15-keto-prostaglandin F in intact and ovariectomized ewes over the time of expected luteal regression Biology of Reproduction $29271-277$

Fairclough RJ, Moore LG, Peterson AJ and Watkins WB (1984) Effect of oxytocin on plasma concentrations of 13,14-dihydro-15-keto-prostaglandin F and the oxytocin-associated neurophysin during the oestrous cycle and early pregnancy in the ewe Biology of Reproduction 31 36-44

Flint APF and Sheldrick EL (1983) Evidence for a systemic role for ovarian oxytocin in luteal regression in sheep journal of Reproduction and Fertility 67 $215-225$

Garrett JE, Geisert RD, Zavy M, Gries LK, Wettemann RP and Buchanan DS (1988) Effect of exogenous progesterone on prostaglandin $F_{2 n}$ release and the interestrous interval in the bovine Prostaglandins 36 (1) 85-96

Ginther OJ (1968) Influence of exogenous progesterone and the uterus on ovarian activity in sheep Endocrinology 83 613-615

Ginther OJ (1969) Length of oestrous cycle and size of corpus luteum in guinea pigs and sheep treated with progesterone at different days of oestrous cycle American Journal of Veterinary Research 30 1975-1978

Ginther OJ (1970) Effect of progesterone on length of estrous cycle in cattle American Journal of Veterinary Research 31 493-496 
Goding JD, McCracken JA and Baird DT (1967) The study of ovarian function in the ewe by means of a vascular autotransplantation technique Journal of Endocrinology 39 (1) 37-52

Homanics GE and Silvia WJ (1988) Effects of progesterone and oestradiol-17ß on uterine secretion of prostaglandin $F_{2 a}$ in response to oxytocin in ovariectomised ewes Biology of Reproduction 38 804-811

Hooper SB, Watkins WB and Thorburn GD (1986) Oxytocin, oxytocinassociated neurophysin and prostaglandin concentrations in the uteroovarian vein in pregnant and non-pregnant sheep Endocrinology 119 2590-2597

Lawson RAS and Cahill LP (1983) Modification of the embryo-maternal relationship in ewes by progesterone treatment early in the oestrous cycle Journal of Reproduction and Fertility $67473-475$

Lewis PE, Kiesling DO and Warren JE (1977) Indomethacin inhibits progesterone-induced luteolysis in ewes American Society of Animal Science 69th Annual Meeting 183 (abstract)

McCracken JA, Carlson JC, Glew ME, Goding JR, Baird DT, Green K and Samuelsson B (1972) Prostaglandin $\mathrm{F}_{2 \alpha}$ identified as a luteolytic hormone in sheep Nature New Biology 238 129-134

McCracken JA, Shramm W and Okulicz WC (1984) Hormone receptor control of pulsatile secretion from the ovine uterus during luteolysis and its abrogation in early pregnancy Animal Reproduction Science 7 31-55

Merriam GR and Wachter KW (1982) Algorithms for the study of episodic hormone secretion American Journal of Physiology 243 E310-E318

Moore LG, Choy VJ, Elliot RL and Watkins WB (1986) Evidence for the pulsatile release of $\mathrm{PGF}_{2 \mathrm{u}}$ inducing the release of ovarian oxytocin during luteolysis in the ewe Journal of Reproduction and Fertility 76 159-166

Morgan GL, Giesent RD, McCann JP, Bazer FW, Ott TL, Mirando MA and Stewart M (1993) Failure of luteolysis and extension of the interoestrous interval in sheep treated with the progesterone antagonist miferpristone (RU 486) Journal of Reproduction and Fertility $\mathbf{9 8} 451-457$

Ottobre JS, Lewis GS, Thayne WV and Inskeep EK (1980) Mechanism by which progesterone shortens the estrous cycle of the ewe Biology of Reproduction 23 1046-1053
Piper PJ, Vane JR and Wyllie JH (1970) Inactivation of prostaglandins by the lungs Nature 225 600-604

Radford HH, Watson RH and Wood GF (1960) A crayon and associated harness for the detection of mating under field conditions Australian Veterinary Journal 36 57-66

Rice GE, Jenkin G and Thorburn GD (1986) Comparison of particle-associated progesterone and oxytocin in the ovine corpus luteum Journal of Endocrinology 108 109-116

Sheldrick EL and Flint APF (1985) Endocrine control of uterine oxytocin receptors in the ewe Journal of Endocrinology 106 249-258

Silvia WJ and Homanics GE (1988) Role of phospholipase C in mediating oxytocin-induced release of prostaglandin $\mathrm{F}_{2 \mathrm{a}}$ from ovine endometrial tissue Prostaglandins 35 535-548

Thomas GB, Oldham CM, Hoskinson RM and Scaramuzzi RJ (1985) Use of active immunization to evaluate the roles of progesterone during the oestrous cycle of the ewe. In Reproduction in Sheep pp 7-9 Eds DR Lindsay, and DT Pearce. Cambridge University Press, London

Vallet JL, Lamming GE and Batten M (1990) Control of endometrial oxytocin receptor and uterine response to oxytocin by progesterone and oestradiol in the ewe Journal of Reproduction and Ferility 90 625-634

Wathes DC and Hamon M (1993) Localization of oestradiol, progesterone and oxytocin receptors in the uterus during the oestrous cycle and early pregnancy of the ewe Journal of Endocrinology 138 479-491

Webb R, Mitchell MD, Falconer J and Robinson JS (1981) Temporal relationships between peripheral plasma concentrations of oxytocin, progesterone and 13,14-dihydro-15-keto prostaglandin $\mathrm{F}_{2 u}$ during the oestrous cycle and early pregnancy in the ewe Prostaglandins 22 443-454

Woody CD and Ginther OJ (1986) Effect of exogenous progesterone on corpora lutea in unilaterally hysterectomized heifers Journal of Animal Science 27 1387-1390

Zhang J, Weston PG and Hixon JE (1992) Role of progesterone and oestradiol in the regulation of uterine oxytocin receptors in ewes Journal of Reproduction and Fertility 94 395-404 